\title{
The Exocyst Complex Associates with Microtubules to Mediate Vesicle Targeting and Neurite Outgrowth
}

\author{
Irving E. Vega ${ }^{1}$ and Shu-Chan Hsu ${ }^{1,2}$ \\ ${ }^{1}$ Department of Biochemistry, University of Medicine and Dentistry of New Jersey, Robert Wood Johnson Medical \\ School, Piscataway, New Jersey 08854, and 2Department of Cell Biology and Neuroscience, Rutgers University, \\ Piscataway, New Jersey 08854
}

During neuronal development, vesicles are targeted to the growth cone to promote neurite outgrowth and synaptogenesis. The Exocyst complex is an essential macromolecule in the secretory pathway that may play a role in vesicle targeting. Although it has been shown that this complex is enriched in rat brain, the molecular mechanism underlying its function is largely unknown. Here, we report that the Exocyst complex coimmunoprecipitates with microtubules from total rat brain lysate. Additionally, the Exocyst complex subcellular localization changes on neuronal differentiation. In undifferentiated pheochromocytoma (PC12) cells, this complex is associated with microtubules at the microtubule organizing center. However, in differentiated PC12 cells and cultured hippocampal neurons, the Exocyst complex and microtubules extend to the growing neurite and colocalize at the growth cone with synaptotagmin. Inhibition of the NGF-activated MAP kinase pathway blocks the Exocyst complex and microtubule redistribution, abolishing neurite outgrowth and promoting cytosolic accumulation of secretory vesicles. Consistently, the overexpression of Exocyst sec10 subunit mutant blocks neurite outgrowth. These results indicate that the Exocyst complex targets secretory vesicles to specific domains of the plasma membrane through its association with the microtubules, promoting neurite outgrowth.

Key words: Exocyst complex; microtubules; exocytosis; vesicle targeting; neurite outgrowth; differentiation; MAP kinase pathway
The secretory pathway is a conserved mechanism that targets proteins destined for secretion or integration into the plasma membrane in a highly ordered manner (Guo et al., 2000). First, secretory and plasma membrane proteins are synthesized in the endoplasmic reticulum and transferred to the Golgi apparatus and subsequently to the trans-Golgi network where they are incorporated into secretory vesicles and sorted for targeting to the plasma membrane (Mellman et al., 1992). It has been shown that microtubules (MTs) and microtubule-associated motors serve as a railway to deliver these vesicles to the plasma membrane (Kamal and Goldstein, 2000). However, it is still unknown how secretory vesicles are targeted to specific domains of the plasma membrane in which docking and fusion take place, resulting in secretion or membrane addition (Sudhoft et al., 1993).

A macromolecule that has been suggested to play a role in targeting secretory vesicles to the plasma membrane is the Exocyst complex (also known as the Sec6/8 complex). This complex is conserved from yeast to mammals (Bowser et al., 1992; Hsu et al., 1996) and is composed of eight subunits (Sec3, Sec5, Sec6, Sec8, Sec10, Sec15, Exo70, and Exo84). In the budding yeast Saccha-

Received Nov. 16, 2000; revised March 15, 2001; accepted March 19, 2001.

This work was supported in part by the Charles and Johanna Busch Memorial Fund and by National Institutes of Health Grant NS38892-01A1 to S.C.H. I.V. is a recipient of a Predoctoral Fellowship from the National Institutes of Health (GM20274-01). I.V. thanks his family for their support during difficult times. We also thank Dr. Robin Davis and Crista Adamson for their technical support with the fluorescence microscope. Anti-GM130 antibody was a gift from Drs. Martin Lowe (University of Manchester, Manchester, UK) and Jesse Hay (University of Michigan, Ann Arbor, MI).

Correspondence should be addressed to Shu-Chan Hsu, Department of Cell Biology and Neuroscience, Rutgers University, Nelson Biological Laboratories, Room D419, 604 Allison Road, Piscataway, NJ 08854. E-mail: hsu@biology. rutgers.edu.

Copyright (C) 2001 Society for Neuroscience $\quad 0270-6474 / 01 / 213839-10 \$ 15.00 / 0$ romyces cerevisiae, mutations in these complex subunits promote cytoplasmic accumulation of secretory vesicles and defects in polarized growth (Bowser et al., 1992; Finger et al., 1998). Additionally, the Exocyst complex has been found to concentrate at sites of membrane addition, such as the bud tip of developing daughter cells (TerBush et al., 1995). Consistently, in cultured hippocampal neurons and pheochromocytoma (PC12) cells, the Exocyst is present at the growth cone where membrane addition takes place (Kee et al., 1997; Hazuka et al., 1999). Furthermore, a delay in neuronal induction was observed in mouse embryos with deletion of the sec 8 gene, suggesting that the Exocyst complex may play a role in neural development (Friedrich et al., 1997). These results suggest that the Exocyst complex may target secretory vesicles to the plasma membrane during cell growth and differentiation. However, the molecular mechanism underlying the Exocyst complex function in vesicle targeting is presently unknown.

On neuronal differentiation, vesicles are targeted to specific areas of the plasma membrane, promoting neurite outgrowth and synaptogenesis. To uncover the role of the Exocyst complex in vesicle targeting, we monitored the subcellular localization and molecular associations of this complex during neuronal differentiation. The Exocyst complex subcellular localization changed on neuronal differentiation in association with MTs. We showed that the Exocyst complex coimmunoprecipitated with MTs from total rat brain lysate and that MTs were also found tightly associated in undifferentiated and differentiated PC12 cells. Interestingly, inhibition of the NGF-activated MAP kinase pathway abolished the Exocyst complex redistribution, suggesting that this complex may play a role in neuronal differentiation. Consistently, the overexpression of an Exocyst complex subunit mutant $\left(\sec 10^{\Delta \mathrm{CT}}\right)$ hin- 
dered neurite outgrowth. These results indicate that the Exocyst complex targets vesicles toward specific plasma membrane domains through its association with MTs, promoting neurite outgrowth and, consequently, neuronal differentiation.

\section{MATERIALS AND METHODS}

\section{Cell culture methodology}

PC12 cells were plated on polylysine-coated plates and maintained in growth medium [DMEM supplemented with $7.5 \%$ fetal calf serum (FCS), $7.5 \%$ horse serum, $3.5 \mathrm{gm} / 1$ glucose, $3.7 \mathrm{gm} / 1$ sodium bicarbonate, $\mathrm{pH} 7.3,10 \mu \mathrm{g} / \mathrm{ml}$ streptomycin, and $10 \mathrm{U} / \mathrm{ml}$ penicillin]. The medium was changed every $2 \mathrm{~d}$ to propagate undifferentiated cells. Nerve growth factor (NGF) $(50 \mathrm{ng} / \mathrm{ml})$ was added directly to the medium to initiate cell differentiation. Undifferentiated and differentiated PC12 cells were cultured at $30-50 \%$ confluency. Cells were incubated for $3 \mathrm{~d}$ in the presence of NGF before they were fixed and permeabilized for immunocytochemistry experiments or harvested for subcellular fractionation.

\section{Antibodies and Western blot}

Recombinant Exo70 was expressed as a glutathione $S$-transferase (GST)fusion protein in Escherichia coli. The recombinant protein was purified by binding to glutathione-coupled beads and eluting from those beads by thrombin cleavage. Soluble Exo70 protein was dialyzed overnight against 500 volumes of PBS and used to immunize $\mathrm{BALB} / \mathrm{c}$ mice for monoclonal antibody generation (Lane et al., 1986). Monoclonal antibodies were obtained from the corresponding hybridoma cell lines that were generated by the fusion of NS-1 myeloma cells with spleen cells from BALB/c mice that were immunized with the recombinant rExo70. Western blot and ELISA were used to test the antibody specificity.

Protein samples were resolved on 10\% SDS-polyacrylamide gels and transferred to nitrocellulose membranes for Western blot analysis. The nitrocellulose membranes were blocked by incubation with $5 \%$ milk in TBST (10 mm Tris, pH 8.0, $150 \mathrm{~mm} \mathrm{NaCl}$, and $0.1 \%$ Tween 20) for $1 \mathrm{hr}$ at room temperature. Primary monoclonal antibodies were used as follows: anti-Exo70 1:1000, anti-Sec8 1:500, anti-Sec6 1:500, anti-transferrin receptor 1:500 (Zymed, San Francisco, CA), anti-syntaxin6 (Syn6) 1:1000, and anti-syntaxin1 (Syn1) 1:1000. Primary polyclonal antibodies were used as follows: anti- $\alpha$-tubulin 1:200 (Sigma, St. Louis, MO), anti-synaptotagamin (Sytg) 1:2000 (Sigma), anti-actin 1:200 (Sigma), and anti-RhoA 1:200 (Santa Cruz Biotechnology, Santa Cruz, CA). After a 1 $\mathrm{hr}$ incubation at room temperature, the membranes were washed three times with TBST and incubated with either goat anti-mouse HRPconjugated secondary antibodies (1:5000; Sigma) or goat anti-rabbit HRP-conjugated secondary antibodies (1:10000; Sigma). Membranes were incubated for $1 \mathrm{hr}$ with secondary antibodies and visualized by enhanced chemiluminescence.

\section{Immunocytochemistry}

Both undifferentiated and differentiated PC12 cells were washed three times with $1 \mathrm{ml}$ of PBS $(1 \times)$ and fixed with $1 \mathrm{ml}$ of methanol (100\%) for $5 \mathrm{~min}$ at $-20^{\circ} \mathrm{C}$. Cells were rehydrated by incubation with $2 \mathrm{ml}$ of PBS $(1 \times)$ for $5 \mathrm{~min}$ at room temperature. After rehydration, cells were permeabilized with DMEM containing $2 \%$ FCS and $0.4 \%$ saponin. Cells were washed three times with PBS and incubated overnight with primary antibodies at $4^{\circ} \mathrm{C}$. Primary antibodies were removed by washing three times with PBS. Secondary antibodies were added and incubated for $1 \mathrm{hr}$ at room temperature. Goat anti-mouse fluorescein-conjugated (FITC; 1:100) or goat anti-rabbit rhodamine-conjugated (TRITC; 1:400) antibodies were used as secondary antibodies. After incubation, secondary antibodies were removed, and cells were washed and mounted in a solution containing 10\% 1,4-diazabicyclo-[2.2.2] octane (Sigma), 10\% PBS $(1 \times)$, and $80 \%$ glycerol. Labeled cells were visualized by inverted fluorescence microscope (Axiovert 135; Zeiss, Thornwood, NY).

\section{Pharmacology}

Microtubule-disrupting drugs were applied as follows: nocodazole (5 $\mu \mathrm{g} / \mathrm{ml}$; Calbiochem, La Jolla, CA) for $30 \mathrm{~min}$; colchicine $(2 \mu \mathrm{M}$; Calbiochem) and vinblastine (2 $\mu \mathrm{M}$; Calbiochem) for $1 \mathrm{hr}$ at $37^{\circ} \mathrm{C}$ in $5 \% \mathrm{CO}_{2}$. Actin filament-disrupting drugs were applied as follows: latrunculin A (5 $\mu \mathrm{M}$; Calbiochem), latrunculin B (10 $\mu \mathrm{M}$; Calbiochem), cythocalasin D $\left(10 \mu \mathrm{M}\right.$; Calbiochem) for $1 \mathrm{hr}$ at $37^{\circ} \mathrm{C}$ in $5 \% \mathrm{CO}_{2}$. After incubation, cells were washed three times with PBS and fixed in methanol (100\%). After fixation, cells were permeabilized and incubated with primary antibodies as described above. Primary antibodies were used as follows: antiacetylated $\alpha$-tubulin monoclonal antibodies (1:50; Sigma), anti-Exo70 monoclonal antibodies (1:100), and anti-actin polyclonal antibodies (1: 100; Sigma). To determine whether the Exocyst complex is associated with the Golgi apparatus, we incubated PC12 cells with the Golgidisrupting drug brefeldin A (BFA; $5 \mu \mathrm{g} / \mathrm{ml}$ ) for $30 \mathrm{~min}$ at $37^{\circ} \mathrm{C}$ in $5 \%$ $\mathrm{CO}_{2}$. The Golgi apparatus and the Exocyst complex were visualized by double staining with anti-Exo70 monoclonal and anti-GM130 polyclonal antibodies [1:100; a gift from Drs. Martin Lowe (University of Manchester, Manchester, UK) and Jesse Hay (University of Michigan, Ann Arbor, MI)]. Undifferentiated PC12 cells were preincubated for $1 \mathrm{hr}$ with the MAP kinase kinase inhibitor PD98059 (30 $\mu \mathrm{M}$; Calbiochem) followed by the addition of NGF $(50 \mathrm{ng} / \mathrm{ml})$ at $37^{\circ} \mathrm{C}$ in $5 \% \mathrm{CO}_{2}$ for $3 \mathrm{~d}$. After incubation, PC12 cells were washed with PBS and fixed as explained above. The MTs and Sytg were visualized by double staining with anti-acetylated $\alpha$-tubulin monoclonal antibody (1:50; Sigma) and anti-Sytg polyclonal antibodies (1:2000; Sigma), respectively. The subcellular localization of the Exocyst complex and Sytg was determined by double staining with anti-Exo70 monoclonal antibody and anti-Sytg (1:2000; Sigma) polyclonal antibodies, respectively.

\section{Subcellular fractionation and immunoprecipitation}

Percoll gradient. Undifferentiated and differentiated PC12 cells were cultured as described above. Cells from three confluent plates were scraped and collected in gradient-lysis buffer (20 mM Tris, $\mathrm{pH}$ 8.0, 250 mM sucrose, and 2 mM EDTA). Harvested cells were passed through a 26 ga syringe three times and homogenized in a Potter-Elvehjem tissue grinder (20 stokes). After homogenization, cells were spun at $2100 \times g$ for $10 \mathrm{~min}$, and the supernatant was collected and spun again at $2100 \times$ $g$ for $5 \mathrm{~min}$. The resulting supernatant (postnuclear fraction) was incubated with DNase (Life Technologies, Gaithersburg, MD) $(1 \mu \mathrm{l} / \mathrm{ml})$ at $37^{\circ} \mathrm{C}$ for $30 \mathrm{~min}$. The Percoll (Sigma) self-generated gradient was prepared by diluting a $90 \%$ Percoll stock solution with the lysis buffer to a final concentration of $17.5 \%$ (Morand et al., 1986). The postnuclear lysate was loaded onto the top of the Percoll gradient, spun at 26,000 $\times$ $g$ for $1 \mathrm{hr}$ in a TLS55 rotor (Beckman Instruments, Fullerton, CA), and halted without the use of brakes. Gradient fractions (150 $\mu$ l per fraction) were collected from the top of the gradient and analyzed by Western blot.

Immunoprecipitation. Anti-Sec8 monoclonal antibody 2E12 or nonspecific mouse immunoglobin was coupled to protein-A beads at a final concentration of $2 \mathrm{mg} / \mathrm{ml}$ using the cross-linker dimethylpimelimidate as previously described (Pevsner et al., 1994). PC12 cell postnuclear lysate was prepared as explained above using lysis buffer (20 mM HEPES, 150 $\mathrm{mm} \mathrm{NaCl}, 2 \mathrm{~mm}$ EDTA, and $1 \mathrm{~mm}$ dithiothreitol). Rat brain postnuclear lysate was prepared by homogenizing the frozen brain in seven volumes of lysis buffer. The lysates were centrifuged twice at $3000 \times g$ to remove intact cells and nuclei. The resulting postnuclear lysates were precleared with protein-A beads $(10 \mu \mathrm{l}$ of protein $\mathrm{G}$ bead per $100 \mu \mathrm{l}$ of protein sample) at $4^{\circ} \mathrm{C}$ for $4 \mathrm{hr}$. The precleared lysates were then incubated with immobilized anti-Sec8 or control antibodies overnight at $4^{\circ} \mathrm{C}$. The next day, beads were washed three times with 10 volumes of the lysis buffer and another three times with the lysis buffer without dithiothreitol. Proteins bound to beads were solubilized in a protein sample buffer containing $10 \%$ SDS and subjected to SDS-PAGE and Western blot analysis.

\section{In vitro protein binding assay}

The Exocyst complex subunits Exo70, Sec6, Sec8, and Sec10 and their mutants Sec ${ }^{\Delta \mathrm{NT}}$ and Sec10 ${ }^{\Delta \mathrm{CT}}$ were subcloned into the bacterial expression vector pGEX-KG and expressed in E. coli bacteria. Recombinant proteins of these constructs were harvested from bacteria by sonication in the lysis buffer (20 mM Tris, $\mathrm{pH} 8.0,2$ mM EDTA, $2 \mathrm{~mm}$ dithiothreitol, $150 \mathrm{~mm} \mathrm{NaCl}$, and $0.1 \%$ Tween 20 ), followed by centrifugation at $18,000 \times g$ for $15 \mathrm{~min}$ at $4^{\circ} \mathrm{C}$. The resulting bacterial lysates were incubated with glutathione-conjugated bead overnight at $4^{\circ} \mathrm{C}$ to purify recombinant proteins. After incubation, these beads were washed three times with the lysis buffer and used for protein binding studies. To obtain soluble recombinant proteins without their GST moiety, some glutathione-conjugated beads with bound GST-fusion proteins were digested with thrombin $(10 \mathrm{ng} / \mathrm{ml}$; Sigma) for $1 \mathrm{hr}$ at room temperature. The digestion was stopped with heparin $(10 \mathrm{ng} / \mathrm{ml}$; Sigma), and the supernatant containing soluble recombinant protein was collected for binding studies. For a typical binding experiment, GST-fusion proteins bound to glutathione-conjugated beads were incubated with soluble recombinant proteins at $4^{\circ} \mathrm{C}$ for $4 \mathrm{hr}$ with constant rotation. After 
incubation, beads were washed three times with the lysis buffer, and proteins bound to beads were analyzed by Western blot.

\section{Molecular biology}

The sec 8 and sec10 truncation constructs were generated by PCR. The Sec8 N-terminal truncation was obtained by amplifying the sec8 sequence from nucleotide 1070 to the end of its open-reading frame at $2915 \mathrm{nt}$. This represents a deletion of the first 339 amino acids in the Sec8 protein sequence. Similarly, the Sec10 C-terminal truncation was obtained by amplifying the sec10 sequence from its first nucleotide to nucleotide 1612 in its open-reading frame. This deletes the last 171 amino acids in the Sec10 protein sequence. PCR primers were designed to introduce a $B g l I I$ site at the $5^{\prime}$ end and a SalI site at the $3^{\prime}$ end of the amplified sequence. Amplified PCR fragments were ligated into BglII/ SalI sites in the pIRES2-EGFP vector (Clontech, Cambridge, UK). Ligation products were introduced into $E$. coli $\mathrm{DH} 5 \alpha$ strain, and positive colonies were identified by restriction digestion.

For PC12 cell transfection, DNA was purified using the QIAfilter (Qiagen, Hilden, Germany) midi-prep kit. PC12 cells were cultured at $80-90 \%$ confluency as explained above. LipofectAMINE 2000 reagent (3 $\mu \mathrm{l}$; Life Technologies) was added to $100 \mu \mathrm{l}$ of OptiMEM medium (Life Technologies) and incubated for $5 \mathrm{~min}$ at room temperature. DNA $(1 \mu \mathrm{g})$ in $100 \mu \mathrm{l}$ of OptiMEM medium was added slowly to the LipofectAMINE 2000-containing solution and incubated for $20 \mathrm{~min}$ at room temperature. After incubation, the transfection mixture was added to PC12 cells in $800 \mu \mathrm{l}$ of OptiMEM. Cells were incubated for $10 \mathrm{hr}$ at $37^{\circ} \mathrm{C}$ in $5 \% \mathrm{CO}_{2}$. The transfection reaction was terminated by changing the medium back to PC12 cell growth medium.

\section{RESULTS}

\section{The Exocyst complex exhibits distinct subcellular localization on neuronal differentiation}

To study the role of the Exocyst complex in neuronal differentiation, monoclonal antibodies against the Exocyst subunit Exo70 were generated. We tested the specificity of the monoclonal anti-Exo70 antibody 70X13F3 by ELISA (data not shown) and Western blot (Fig. 1 $A$ ). The anti-Exo70 monoclonal antibody recognized a single polypeptide in total rat brain lysate (Fig. $1 A$, lane 1) at the same molecular weight as the purified recombinant Exo70 (Fig. 1A, lane 2). Because the Exocyst subunits are always found associated in the complex (Hsu et al., 1996), this antibody was used as a marker to monitor the intracellular distribution of the Exocyst complex in all subsequent studies.

The rat adrenal PC12 cell line is a very well established system to study the process of neuronal differentiation (Greene et al., 1976; Pang et al., 1995). These cells can be cultured in undifferentiated and NGF-induced differentiated stages. We used the monoclonal anti-Exo70 antibody to determine the subcellular localization of the Exocyst complex during neuronal differentiation. Interestingly, in undifferentiated PC12 cells (Fig. 1B, arrow), the Exocyst complex exhibited a perinuclear localization. This perinuclear localization of the Exocyst complex is indicative of a potential association with the Golgi network or the MT organizing center (MTOC). However, in differentiated PC12 cells (Fig. $1 C$ ) and cultured hippocampal neurons (data not shown), this complex is found at the cell body (Fig. $1 C$, arrowhead), in the extending neurite, and concentrated at the growth cone (Fig. $1 C$, arrow). These observed changes in the subcellular localization on neuronal differentiation represent a phenomenon of the entire Exocyst complex because monoclonal antibodies against other Exocyst subunits, Sec6, Sec10, and Exo84, also detected the same redistribution (data not shown). These results indicate that, in response to neuronal differentiation, the Exocyst complex biological function requires its redistribution from the perinuclear localization toward areas of high exocytosis activity, such as the growth cone.
A
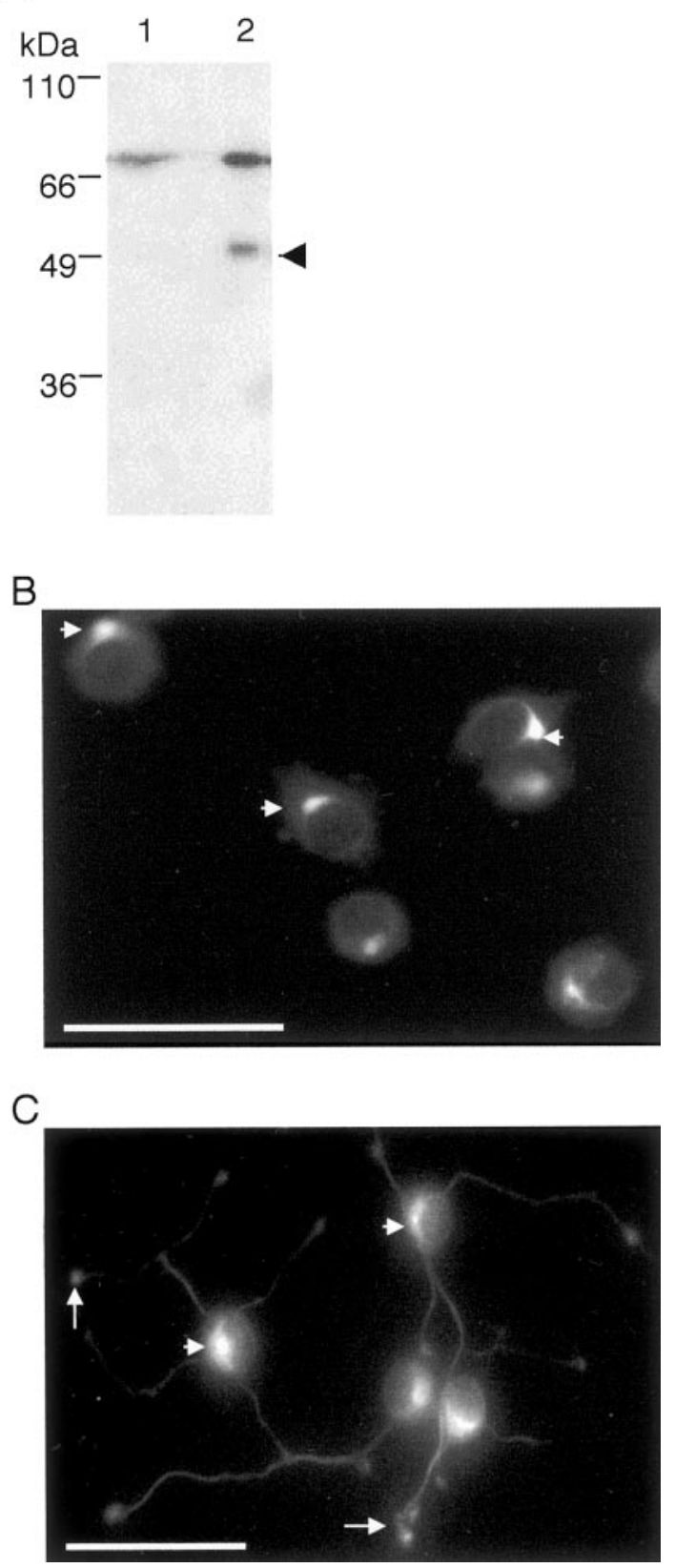

Figure 1. The Exocyst complex exhibits distinct subcellular localization on neuronal differentiation. Monoclonal antibody against the Exocyst complex subunit Exo70 was produced as explained in Materials and Methods. $A$, Western blot analysis using the anti-Exo70 monoclonal antibody $70 \mathrm{X} 13 \mathrm{~F} 3$ showed that it recognized a single band in brain lysate (lane 1). Recombinant Exo70 was used as a molecular weight control (lane 2). The arrow indicates a degradation product of the recombinant Exo70. $B, C$, The subcellular localization of the Exocyst complex in both undifferentiated $(B)$ and differentiated $(C$; NGF; $50 \mathrm{ng} / \mathrm{ml})$ PC12 cells was determined by immunofluorescence microscopy. PC12 cells were fixed with $100 \%$ methanol, and the anti-Exo70 antibody was visualized with anti-mouse antibodies conjugated to FITC. $B$, The Exocyst complex exhibited a perinuclear localization in undifferentiated PC12 cells (arrowheads). C, In differentiated PC12 cells, the Exocyst complex is found in the cell body (arrowheads), along the neurite, and at the growth cone (arrows). Scale bars, $50 \mu \mathrm{m}$. 
Figure 2. Brefeldin A does not affect the Exocyst complex perinuclear localization. The localization of Exo70 $(A, D, G, J)$ and the Golgi marker GM130 protein $(B, E, H, K)$ in undifferentiated $(A-F)$ and differentiated $(G-L)$ PC12 cells was determined by immunofluorescence microscopy. PC12 cells were treated with methanol $(0.5 \%$, Control $)(A-C, G-I)$ or brefeldin A $(5 \mu \mathrm{g} / \mathrm{ml}$ in methanol) $(D-F, J-L)$ as explained in Materials and Methods. The anti-Exo70 antibody was visualized using anti-mouse antibodies conjugated to FITC. Antibodies against GM130 were visualized with anti-rabbit antibodies conjugated to TRITC. Arrows in $G, I, J$, and $L$ show the Exocyst complex at the growth cone. Scale bars, $50 \mu \mathrm{m}$.
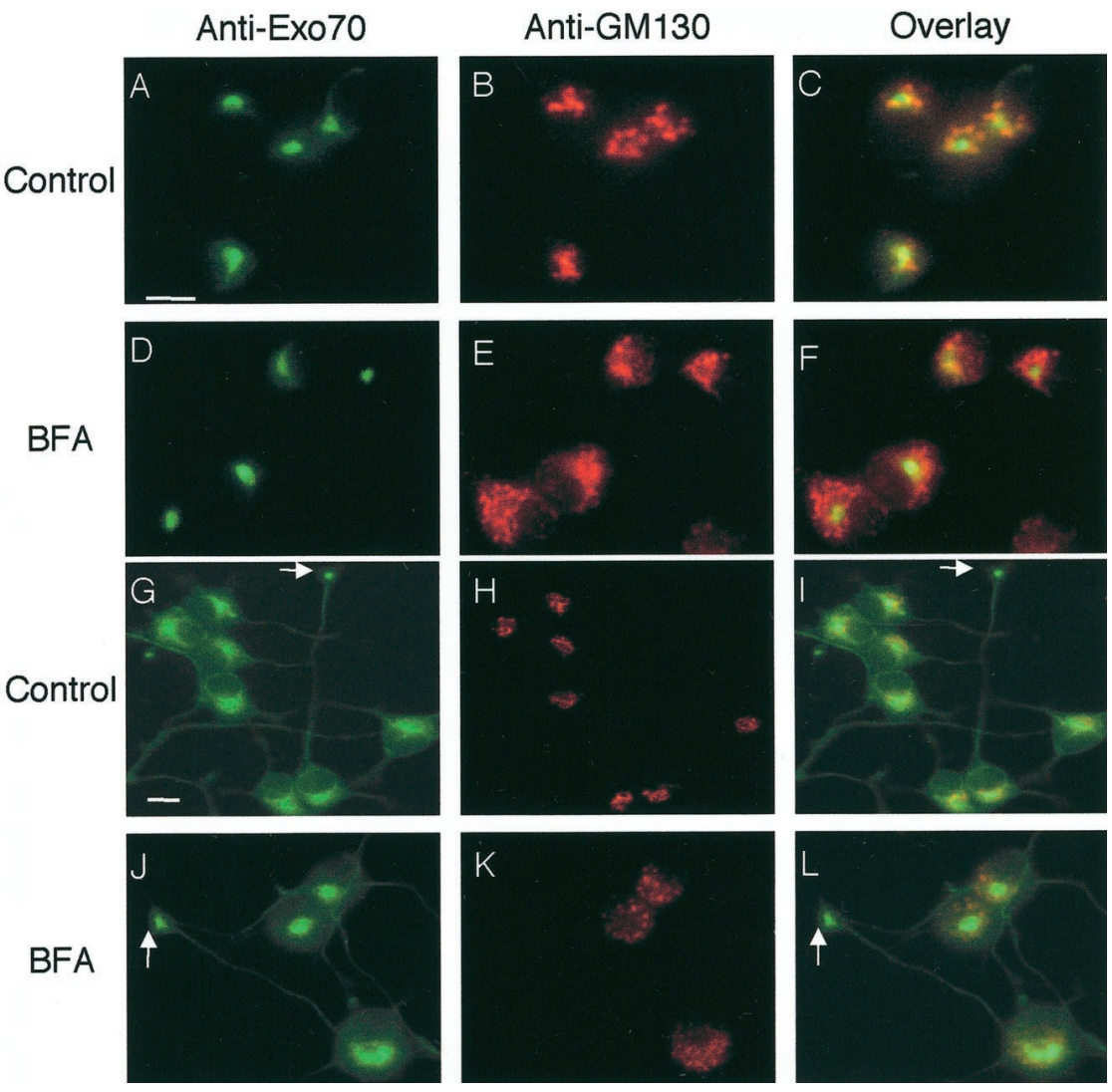

\section{Brefeldin A does not affect the Exocyst complex perinuclear localization}

It has been shown that the trafficking of vesicles from the Golgi network to the growth cone is required for neurite outgrowth (Dai et al., 1995). The perinuclear localization of the Exocyst complex and its redistribution on activation of neuronal differentiation suggest that it may play a role in directing vesicles from the Golgi network to specific plasma membrane domains at the growth cone. To determine whether the subcellular localization of the Exocyst complex coincides with that of the Golgi apparatus, undifferentiated and differentiated PC12 cells were doublestained with antibodies against Exo70 (Fig. $2 A, G$ ) and a Golgi protein, GM130 (Lowe et al., 2000) (Fig. 2B, $H$ ). Interestingly, we observed that in both undifferentiated (Fig. $2 C$ ) and differentiated (Fig. 2I) PC12 cells, the Exocyst complex was in close proximity to the Golgi apparatus. These results suggest that the Exocyst complex might be localized close to or at the Golgi network to target vesicles toward the growth cone on neuronal differentiation.

To confirm the association of the Exocyst complex with the Golgi apparatus, undifferentiated and differentiated PC12 cells were exposed to the Golgi-disrupting drug BFA (Mellman et al., 1992). As expected, BFA promoted a diffusion of the GM130 localization (Fig. 2, compare $B, E$, and $H, K$ ). However, the subcellular localization of the Exocyst complex in undifferentiated (Fig. $2 A, \mathrm{D}$ ) and differentiated (Fig. $2 G, J$ ) PC12 cells remained unperturbed. Consistently, it has been shown that in pancreatic acinar cells the Exocyst complex also exhibited a perinuclear localization, which was not affected by BFA (Shin et al., 2000). These results indicate that, although the Exocyst complex is in close proximity to the Golgi apparatus, it is not associated with this organelle.

\section{Microtubule-disrupting drugs affect the subcellular localization of the Exocyst complex}

The perinuclear localization of the Exocyst complex is not caused by its association with the Golgi apparatus (Fig. 2). This observation indicates that the Exocyst complex may be associated with a specific cellular component in the cytosol that redistributes during neuronal differentiation. It has been shown that the MTOC has a perinuclear localization in close proximity to the Golgi network (Brinkley et al., 1985). Additionally, MTs emanate from this specialized region toward the extending neurite and are required to deliver vesicles to the growth cone (Dent et al., 1999). To determine whether the Exocyst complex is associated with MTs near or at the MTOC, undifferentiated PC12 cells were treated with microtubule-disrupting drugs. As control, undifferentiated PC12 cells were also treated with actin-disrupting drugs. Treated PC12 cells could recover completely after the drugs were washed away so that any observed change in subcellular localization was not caused by cells undergoing necrosis or apoptosis. The subcellular localization of the Exocyst complex (Fig. $3 A, B, C$ ), MTs (Fig. 3D,E,F), and actin-filaments (Fig. 3G, $H, I$ ) was monitored before and after drug treatments. In untreated cells, the Exocyst complex (Fig. $3 A$ ) exhibited a perinuclear localization, and the actin-filaments (Fig. $3 G$ ) formed a ring adjacent to the plasma membrane. Interestingly, the MTs exhibited a diff use cytosolic localization with a perinuclear concentration (Fig. 3D, arrow), indicative of the MTOC (Brinkley et al., 1985). These observations indicate that the Exocyst complex may be associated with MTs near or at the MTOC.

When undifferentiated PC12 cells were incubated with the microtubule-disrupting drugs nocodazole (Fig. 3C,F,I), colchicine (data not shown), or vinblastine (data not shown), MTs were 


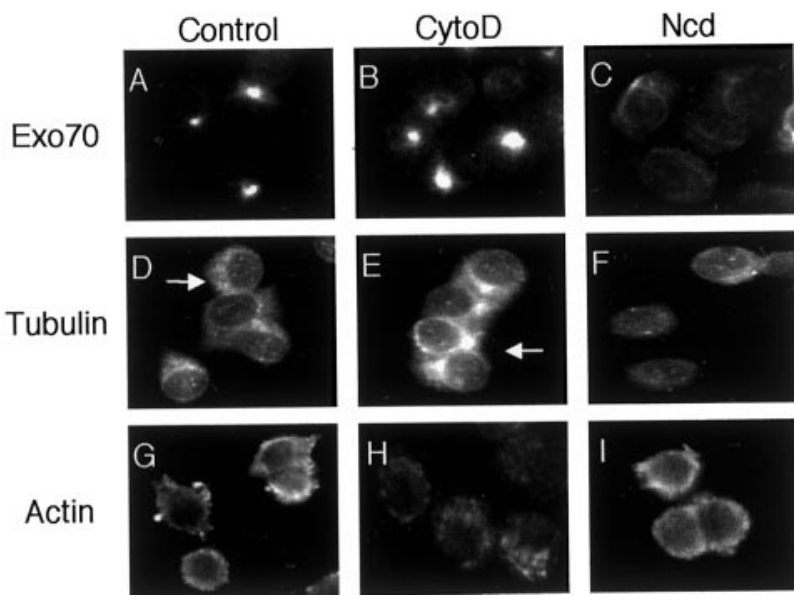

Figure 3. Microtubule-disrupting drugs affect the Exocyst complex perinuclear localization. Undifferentiated $\mathrm{PC} 12$ cells were treated with DMSO $(0.5 \%$; Control $)(A, D, G)$, cytochalasin D $(C y t o D ; 10 \mu \mathrm{M})(B, E$, $H)$, or Nocodazole $(N c d ; 5 \mu \mathrm{g} / \mathrm{ml})(C, F, I)$ as described in Materials and Methods. After the drug treatment, cells were fixed in methanol, and the localization of Exo70 $(A-C)$, tubulin $(D-F)$, and actin $(G-I)$ was determined. The arrow in $D$ indicates the location of the MTOC. Anti-Exo70 and anti-acetylated $\alpha$-tubulin antibodies were visualized using anti-mouse antibodies conjugated to FITC, and anti-actin polyclonal antibodies were visualized with anti-rabbit antibodies conjugated to TRITC.

found spreading throughout the cytosol with no enrichment at the perinuclear region (Fig. 3, compare $D, F$ ). Interestingly, these drugs also disrupted the perinuclear localization of the Exocyst complex (Fig. 3, compare $A, C$ ) in most PC12 cells. Actin filaments, as expected, were not affected (Fig. 3I). However, cytochalasin D (Fig. 3, compare $G, H$ ), latrunculin A (data not shown), and latrunculin B (data not shown) affected the actin filament distribution but did not disrupt the Exocyst complex (Fig. 3, compare $A, B$ ) or the MT subcellular localization (Fig. 3, compare $D, E)$. These results indicate that the Exocyst complex subcellular localization is dependent on the integrity of MTs. Additionally, these results suggest that the Exocyst complex may be associated, directly or indirectly, with MTs.

\section{The Exocyst complex is associated with microtubules}

The above pharmacological studies suggest that the Exocyst complex may be associated with MTs. Furthermore, the Exocyst complex redistribution on neuronal differentiation suggests that this complex spreads toward the developing neurite and the growth cone with MTs to promote the targeting of secretory vesicles to specific areas of the plasma membrane. Previously, it has been shown that the Exocyst complex is found in the membrane fraction after high-speed centrifugation. Consistently, we have found that the Exocyst complex and MTs were present in the membrane fraction (data not shown).

To further define the subcellular localization of the Exocyst complex, PC12 cell lysate was fractionated in a self-generating Percoll gradient (Fig. 4A). After $3 \mathrm{~d}$ in the presence of NGF (50 $\mathrm{ng} / \mathrm{ml}$ ), PC12 cells were harvested, homogenized, and centrifuged at $2,100 \times g$ to yield a postnuclear fraction. The lysate was loaded on top of a $17.5 \%$ Percoll gradient and spun at 26,000 $\times$ $g$ for $1 \mathrm{hr}$. Gradient fractions were collected and analyzed by Western blot (Fig. 4A). We found that the Exocyst subunits Sec6, Sec8, and Exo70 all migrated to the same fractions, indicating their tight association in the complex. The Exocyst complex subunits showed a major migration peak at fractions 3 and 4 and a small migration peak at fractions 6 and 7 (Fig. 4A). The plasma membrane marker Syn1 (Bennett et al., 1992) and the Golgi/endosome markers transferrin receptor (TfR) and Syn6 (Bock et al., 1997) exhibited a migration peak at fractions 6 and 7 (Fig. 4A). Interestingly, tubulin comigrated with the Exocyst complex throughout the gradient (Fig. 4A). However, the other major cytoskeletal element, actin, comigrated with the soluble protein RhoA (Kaibuchi et al., 1999) in fractions 1-3 (Fig. 4A). Additionally, the bulk of the vesicle marker Sytg (Sudhoft et al., 1993) also comigrated with the Exocyst complex and MTs (Fig. $4 A$ ). Identical Percoll density gradient centrifugation was also performed for undifferentiated PC12 cells and the same results were observed (data not shown). The same migration profile on Percoll gradient was also observed for cultured hippocampal neurons (our unpublished data). These observations demonstrate two important details about the Exocyst complex. First, the majority of the Exocyst complex is not associated with the Golgi apparatus or the plasma membrane. Second, the molecular association of the Exocyst complex does not change during cellular differentiation, although its intracellular localization is altered. These results suggest that the Exocyst complex associates with the same cellular components before and after cellular differentiation. The association of the Exocyst complex with MTs in close proximity to the MTOC may explain the tight perinuclear localization of the complex in undifferentiated PC12 cells. In differentiated PC12 cells, it is likely that the Exocyst complex radiates outward from its perinuclear localization toward the growth cone by its association with MTs emanating from the MTOC. This may explain why the Exocyst complex showed the same density profile on Percoll gradient centrifugation in both undifferentiated and differentiated PC12 cells.

To investigate further the association between the Exocyst complex and MTs, we subjected PC12 cells and rat brain postnuclear lysate to immunoprecipitation with anti-Sec8 monoclonal antibody 2E12 (Fig. 4B,C). The anti-Sec8 antibody (Fig. 4B, $C$, lane 3), but not nonspecific mouse immunoglobulin (Fig. $4 B, C$, lane 2), immunoprecipitated the Exocyst complex from PC12 cells and rat brain postnuclear lysate as shown by the coimmunoprecipitation of the Exocyst subunits Sec8 and Exo70 (Fig. 4B, $C$, lane 3). As expected, tubulin was coimmunoprecipitated specifically with the Exocyst complex (Fig. 4B,C, lane 3). However, actin, the other major cytoskeletal protein, was not observed coimmunoprecipitating with the Exocyst complex (Fig. 4B,C, compare lanes 1, 3). In addition, the Exocyst complex coimmunoprecipitated with septins and Syn1 as previously reported (Hsu et al., 1996, 1998) (data not shown). These results confirm the association between the Exocyst complex and MTs and indicate that this association is physiologically important. Interestingly, the vesicle marker Sytg did not coimmunoprecipitate with the Exocyst complex (Fig. 4B,C, compare lanes 1,3). This is consistent with previous results showing that antibodies against another vesicle marker SV2 did not immunoprecipitate the Exocyst complex (Hsu et al., 1996). Although the Exocyst complex did not coimmunoprecipitate with Sytg, they both comigrated in the Percoll density gradient. These data suggest that the Exocyst complex may be associated, directly or indirectly, with MTs to target the delivery of secretory vesicles toward specific areas of the plasma membrane. 
A

Figure 4. The Exocyst complex is associated with MTs. Subcellular fractionation in a $17.5 \%$ Percoll self-generating gradient $(A)$ and immunoprecipitation $(B-C)$ studies were performed to determine the subcellular localization and microtubule association of the Exocyst complex. $A$, Subcellular fractionation of differentiated PC12 cells on a $17.5 \%$ Percoll gradient was performed as described in Materials and Methods. Gradient fractions were analyzed by Western blot (see Materials and Methods). $B, C$, Western blot analysis of $\mathrm{PC} 12$ cell $(B$, lane 1$)$ and rat brain lysates ( $C$, lane 1$)$ were performed after immunoprecipitation with nonspecific mouse immunoglobulin ( $B, C$, lane 2$)$ or antiSec8 monoclonal antibody 2E12 $(B, C$, lane 3). PC12 cell and rat brain lysates were prepared as described in Materials and Methods.

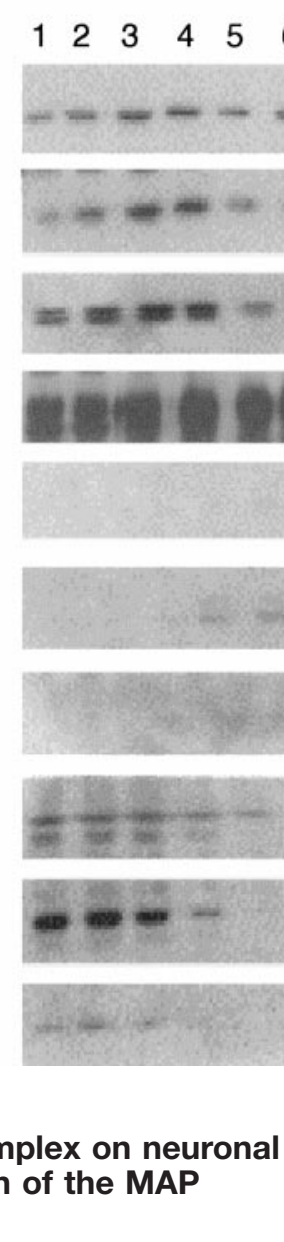
differentiation is blocked by inhibition of the MAP kinase pathway

The neurotrophin NGF binds to the Trk A receptor, which activates the MAP kinase pathway to induce neuronal differentiation (Kaplan et al., 2000). It has been demonstrated that MTs are required for polarized cell growth and undergo reorganization in response to cell differentiation (Dent et al., 1999). Additionally, it has been shown that MTs serve as a railway to deliver secretory vesicles to the growth cone in which membrane addition takes place (Dai et al., 1995; Futerman et al., 1996; Zakharenko et al., 1998). In differentiated PC12 cells, MTs were found along the neurite and at the growth cone (Fig. 5A, arrows) with the vesicle marker Sytg (Fig. 5B,C, arrows). Consistently, the Exocyst complex was also found in the growing neurite and at the growth cone (Figs. $1 C, 5 G$, arrows) in which it colocalized with Sytg (Fig. $5 H, I$, arrows). The association of the Exocyst complex with MTs and changes in their localization in response to NGF-induced cell differentiation bring up the possibility that the Exocyst complex may control the redistribution of MTs to target secretory vesicles toward the growth cone.

To directly test whether the Exocyst complex redistribution is linked to the neuronal differentiation process, we used a protein kinase inhibitor that blocks the MAP kinase pathway. It has been shown that the drug PD98059, which inhibits the activation of the MEK1 protein in the MAP kinase pathway, blocks NGF-induced neuronal differentiation in PC12 cells (Pang et al., 1995). Undifferentiated PC12 cells were treated with PD98059 for 1 hr before the addition of NGF to the growth medium. After PC12 cells were incubated in the presence of NGF-PD98059 for $3 \mathrm{~d}$, the localization of the Exocyst complex, MTs, and the vesicle marker Sytg was determined by immunofluorescence microscopy. As
Sec8

Sec6

\section{Exo70}

Sytg
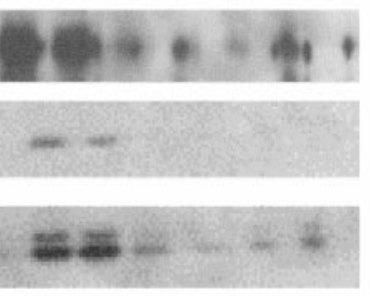

Syn 1

Syn6

Tubulin

Actin

RhoA
B

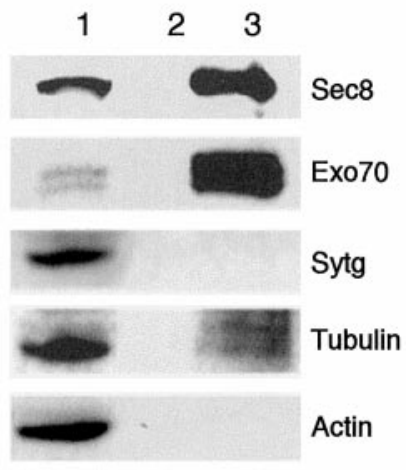

C

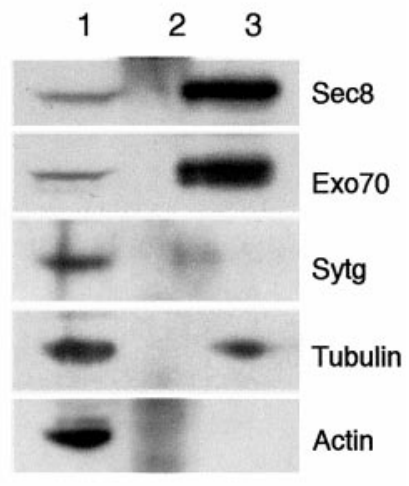

expected, most of the PC12 cells treated with PD98059 did not develop neurites. Interestingly, PD98059 abolished the MTs (Fig. 5, compare $A, D$ ) and the Exocyst complex (Fig. 5, compare $G, J$ ) redistribution normally observed in differentiated PC12 cells. Instead, both MTs (Fig. 5D, arrowheads) and the Exocyst complex (Fig. 5J, arrowheads) exhibited a tight perinuclear localization. Importantly, the vesicle marker Sytg was enriched at the perinuclear region in which the Exocyst complex and MTs were localized (Fig. $5 K, L$, arrowheads), indicating that the majority of vesicles were not able to reach the plasma membrane. These results indicate that the redistribution of the Exocyst complex is linked to the NGF-induced cell-signaling pathway.

\section{The Exocyst complex function is important for neurite outgrowth}

The above studies suggest that the Exocyst complex may be a downstream effector in the NGF-induced neuronal differentiation process. The Exocyst complex may respond to cellular signals to promote the remodeling of MTs toward specific areas of the plasma membrane. Subsequently, the redirected MTs can facilitate the delivery of secretory vesicles to the growth cone, promoting neurite outgrowth. On the basis of this hypothesis, disruption of the Exocyst complex function should abolish neurite outgrowth. As a first step to test this hypothesis, we studied the Exocyst subunit interaction by in vitro protein binding experiments.

The Exocyst complex subunits Exo70, Sec10, Sec8, and Sec6, as well as a Sec8 N-terminal truncation mutant ( $\Delta 1-339 \mathrm{aa}$, Sec8 $\left.{ }^{\Delta N T}\right)$ and a Sec10 C-terminal truncation mutant $(\Delta 536-709$, Sec10 ${ }^{\triangle \mathrm{CT}}$ ), were subcloned into a bacterial expression vector (pGEX-KG). These recombinant proteins were purified from bacterial lysates after incubation with glutathione-conjugated 

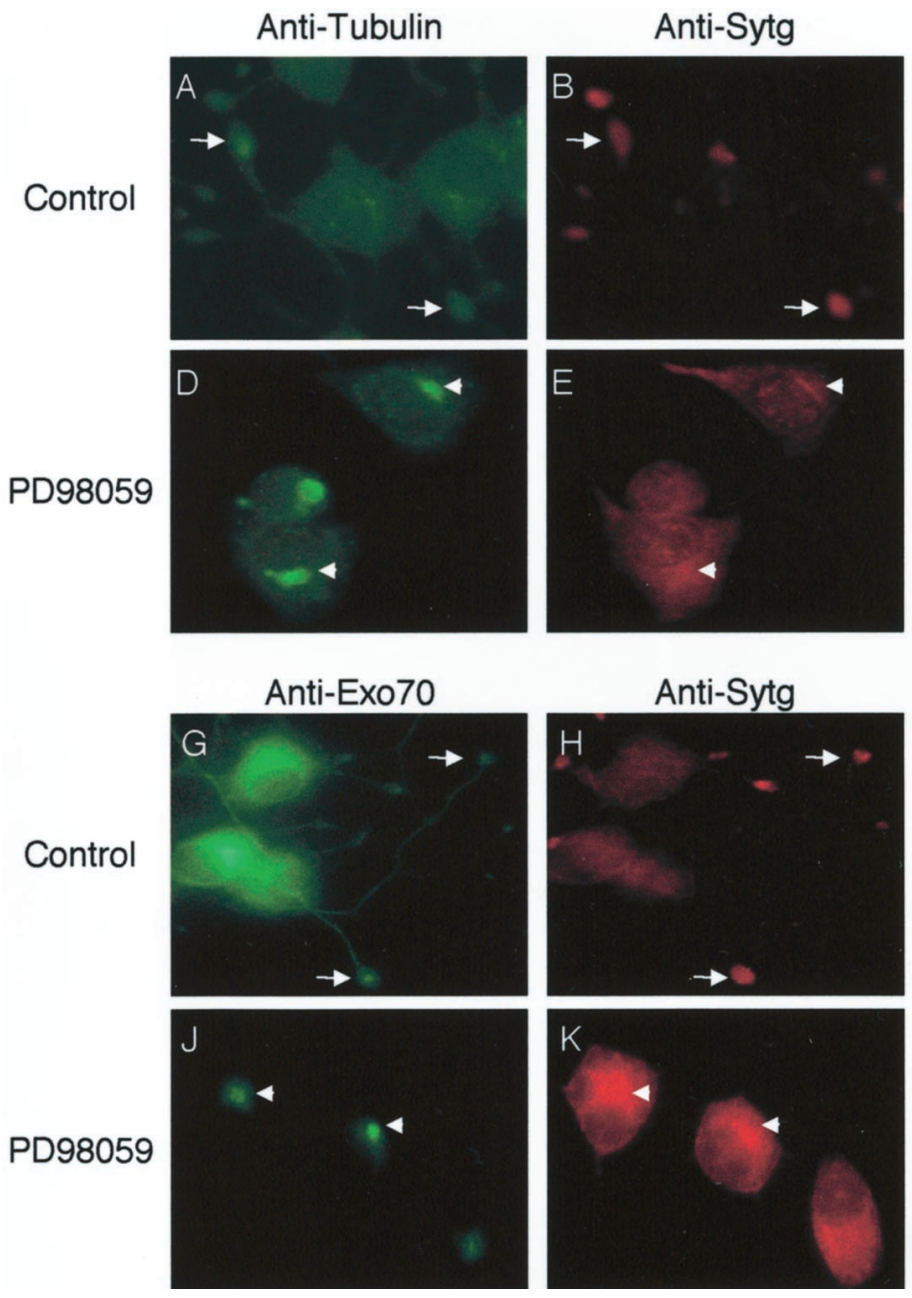

beads. The wild-type GST-Sec8 and GST-Sec10 proteins, as well as the mutants GST-Sec $8^{\Delta \mathrm{NT}}$ and GST-Sec $10^{\Delta \mathrm{CT}}$, were used as baits in the in vitro binding studies. Beads containing GST alone were used as control (Fig. 6A, lanes 13-16). The other GSTfusion proteins were released from their GST moiety by thrombin digestion, and the resulting soluble proteins were collected for the in vitro binding studies. Soluble recombinant proteins were incubated with GST-fusion proteins bound to glutathione-conjugated beads at $4^{\circ} \mathrm{C}$ for $4 \mathrm{hr}$. After incubation, these beads were washed thoroughly to remove unbound proteins. Proteins bound to beads were resolved on $10 \%$ SDS polyacrylamide gels and analyzed by Western blot. We found that Sec6, Exo70, and Sec10 interact with GST-Sec8 (Fig. 6A, lanes 1, 2, and 3, respectively), with Sec10 being the strongest binding partner for Sec8. Interestingly, deletion of the N-terminal domain of the Sec8 protein (GST$\mathrm{Sec} 8^{\Delta \mathrm{NT}}$ ) disrupted its interaction with Sec6 (Fig. $6 \mathrm{~A}$, compare lanes 1,4) and slightly reduced its interaction with Exo70 (Fig. $6 A$, compare lanes 2,5 ). However, the interaction between GSTSec 8 and Sec10 was not affected (Fig. $6 A$, compare lanes 3,6 ) by the $\mathrm{N}$-terminal truncation. These results suggest that deletion of the N-terminal of Sec8 affects its interaction with Sec6 but not its association with Exo70 and Sec10 subunits.

Similar binding experiments were also performed with GSTSec10 (Fig. 6A, lanes 7-9) and GST-Sec10 ${ }^{\Delta \mathrm{CT}}$ (Fig. 6A, lanes 10-12). Both GST-Sec10 and GST-Sec10 ${ }^{\Delta \mathrm{CT}}$ bound to glutathione-conjugated beads were incubated with soluble Sec8 (Fig. 6A, lanes 7, 10), Sec6 (Fig. 6A, lanes 8, 11), and Exo70 (Fig.
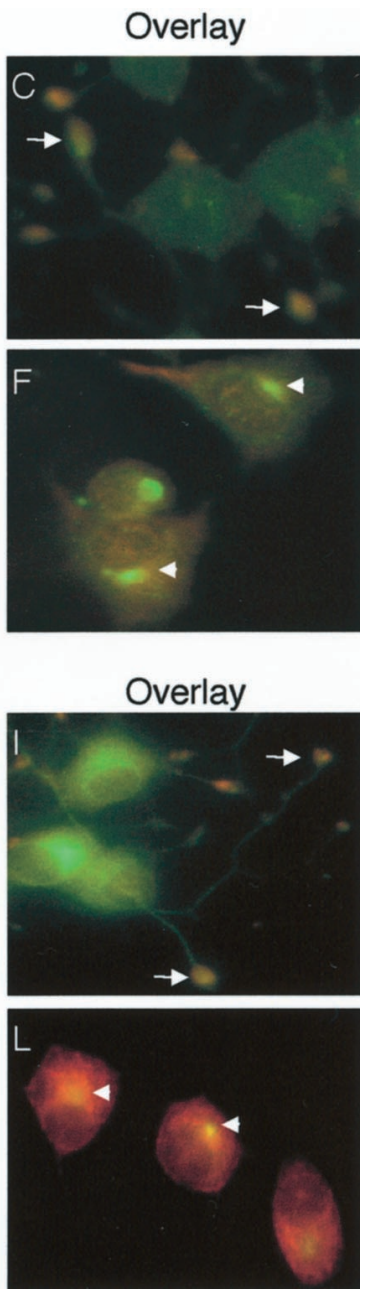

Figure 5. The redistribution of the Exocyst complex on neuronal differentiation is blocked by inhibition of the MAP kinase pathway. Undifferentiated PC12 cells were preincubated for $1 \mathrm{hr}$ with $30 \mu \mathrm{M}$ MAP kinase kinase inhibitor PD98059 in DMSO $(D-F, J-L)$ or with DMSO alone $(A-C, G-I)(0.001 \%)$, followed by coincubation with NGF $(50 \mathrm{ng} / \mathrm{ml})$ for $3 \mathrm{~d}$. The subcellular localization of MTs $(A, D)$, the Exocyst complex $(G, J)$, and the vesicle marker synaptotagmin $(S y t g)(B, E, H, K)$ was determined (see Materials and Methods). The arrows indicate the growth cones of differentiated PC12 cells in $A-C$ and $G-I$. The arrowheads indicate the perinuclear localization of MTs $(D)$ and the Exocyst complex $(J)$ after the drug treatment.

$6 A$, lanes 9,12$)$. As expected from the previous experiment, we found that GST-Sec10 strongly interacted with Sec8 (Fig. 6A, lane 7). Additionally, GST-Sec10 and GST-Sec $10^{\Delta \mathrm{CT}}$ also interacted with Sec6 and Exo70 (Fig. 6A, lanes 8, 9, 11, 12). Interestingly, however, deletion of the Sec10 C-terminal domain abolished its interaction with Sec8 (Fig. 6A, compare lanes 7, 10) and significantly enhanced its interaction with Sec6 (Fig. 6A, compare lanes $8,11)$. The weak interaction detected between GST-Sec10 ${ }^{\Delta \mathrm{CT}}$ and $\operatorname{Sec} 8$ was not significant because the same level of interaction was observed between Sec8 and control GST beads (Fig. 6A, compare lanes 10,13). These results indicate that the $\mathrm{C}$-terminus of Sec10 may be required for its interaction with Sec8. Additionally, the deletion of Sec10 C-terminus may expose a domain required for its interaction with Sec6, thus strengthening the interaction between these two subunits. Interestingly, it has been shown that a deletion of the last 283 amino acids of Sec10 $\left(\operatorname{Sec} 10^{\Delta \mathrm{C}}\right)$ created a dominant negative mutant in the budding yeast $S$. cerevisiae. This mutant could compete with the wild-type Sec10 for interaction with other Exocyst subunits, affecting growth and promoting accumulation of vesicles (Roth et al., 1998). On the basis of these observations, the introduction of $\sec 8^{\Delta \mathrm{NT}}$ or $\sec 10^{\Delta \mathrm{CT}}$ into PC12 cells is likely to compete with endogenous Exocyst complex subunits to disrupt the complex formation and thus hinders its function.

To determine the significance of the Exocyst complex function in neurite outgrowth, PC12 cells were transfected with the Exocyst subunit mutant $\sec 8^{\Delta \mathrm{NT}}$ or $\sec 10^{\Delta \mathrm{CT}}$. We subcloned these 
A

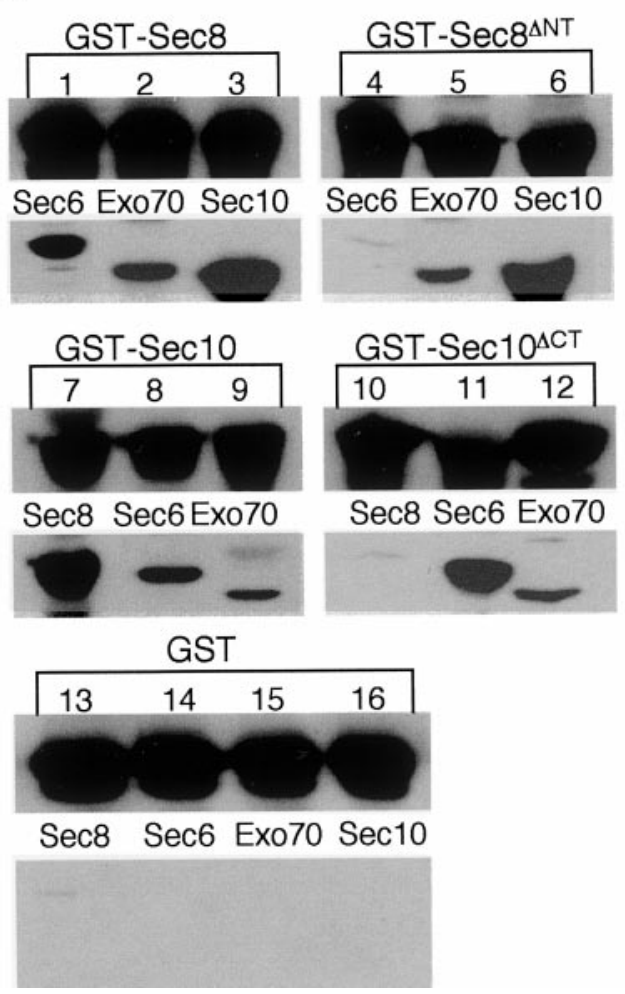

B
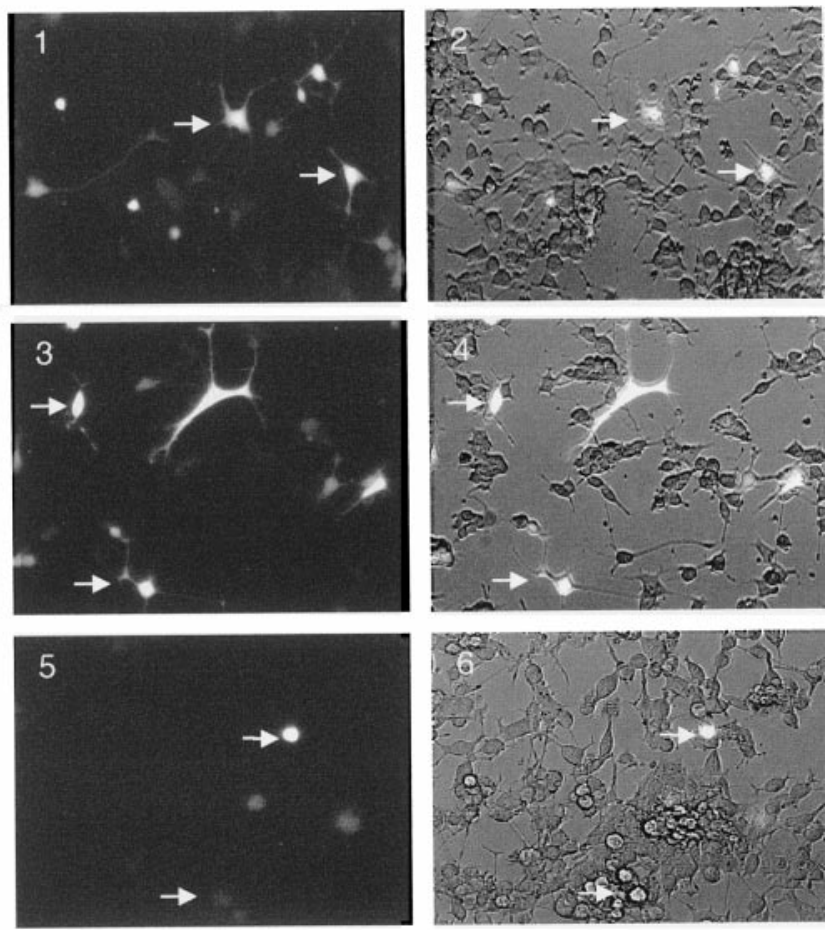

Figure 6. The Exocyst complex function is important for neurite outgrowth. A, Recombinant GST-Sec8 (lanes 1-3) and GST-Sec8 ${ }^{\Delta \text { NT }}$ (lanes $\left.4-6\right)$ were incubated with Sec6 (lanes 1, 4), Exo70 (lanes 2, 5), and Sec10 (lanes 3, 6). GST-Sec10 (lanes 7-9) and GST-Sec10 ${ }^{\Delta \mathrm{CT}}$ (lanes 10-12) were incubated with Sec8 (lanes 7,10), Sec6 (lanes 8,11), and Exo70 (lanes 9,12). GST was used as a negative control (lanes 13-16). Binding experiments were performed and analyzed as explained in Materials and Methods. B, PC12 cells were transfected with pIRES2-EGFP (1, 2), pIRES2-EGFP::sec8 ${ }^{\Delta \text { NT }}$ (3, 4$)$, or pIRES2-EGFP::sec10 ${ }^{\Delta \mathrm{CT}}(5,6)$. NGF $(50 \mathrm{ng} / \mathrm{ml})$ was added $48 \mathrm{hr}$ after transfection. The EGFP expression and cell morphology were monitored under fluorescence $(1,3,5)$ or bright field $(2,4,6) 3 \mathrm{~d}$ after NGF addition (see Materials and Methods). Arrows identify the same cells observed in fluorescence and bright fields.

Exocyst subunit mutants into the mammalian high-expression vector pIRES2-EGFP (Clontech). The pIRES2-EGFP plasmid is a bicistronic vector that allows the expression of both enhanced green-fluorescence protein (EGFP) and an Exocyst subunit mutant as two separate proteins. PC12 cells were transfected with pIRES2-EGFP (Fig. 6B, panels 1, 2), pIRES2-EGFP::sec $8^{\Delta \mathrm{NT}}$ (Fig. 6B, panels 3, 4), and pIRES2-EGFP::sec10 ${ }^{\Delta \mathrm{CT}}$ (Fig. 6B, panels 5, 6). Transfected PC12 cells were identified after $48 \mathrm{hr}$ as cells containing a diff use cytosolic green fluorescence. PC12 cells were further incubated in the presence of fresh medium containing NGF to promote differentiation.

NGF-treated PC12 cells were observed under fluorescence (Fig. 6B, panels 1,3,5) or bright field (Fig. 6B, panels 2, 4,6). PC12 cells transfected with pIRES2-EGFP (Fig. 6B, panels 1, 2, arrows) as well as untransfected cells (cells that are not brightly lit in Fig. 6B, panel 2) differentiated normally. Thus, EGFP overexpression did not inhibit neuronal differentiation. Similarly, PC12 cells transfected with pIRES2-EGFP::sec $8^{\Delta \mathrm{NT}}$ (Fig. 6B, panels 3, 4 , arrows) underwent neuronal differentiation. It is possible that the deletion of a large portion of the Sec8 N-terminal domain $\left(\mathrm{Sec} 8^{\Delta \mathrm{NT}}\right)$ rendered this protein unstable and consequently susceptible to degradation. Because the overexpression of this Exocyst complex subunit mutant did not cause toxicity in PC12 cells, it was used as an internal control for our experiment. In contrast, pIRES2-EGFP::sec10 ${ }^{\Delta \mathrm{CT}}$ inhibited neurite outgrowth in the majority of transfected cells (Fig. 6B, panels 5, 6, arrows). However, neighboring untransfected cells could still extend neurites in response to NGF (Fig. 6B, panel 6), indicating that the inhibition of neurite outgrowth was attributable to the overexpression of the $\sec 10^{\Delta \mathrm{CT}}$ mutant and not to changes in the medium. We consistently obtained a much lower transfection efficiency with pIRES2-EGFP::sec10 $10^{\Delta \mathrm{CT}}$ than with pIRES2-EGFP and pIRES2-EGFP::sec $8^{\Delta \mathrm{NT}}$. This observation suggests that the overexpression of $\sec 10^{\Delta \mathrm{CT}}$ may be detrimental to PC12 cells. Importantly, however, PC12 cells were observed for a period of 2 weeks after the induction of neuronal differentiation, and cells transfected with pIRES2-EGFP::sec10 ${ }^{\triangle \mathrm{CT}}$ lived as long as those cells transfected with pIRES2-EGFP or pIRES2-EGFP::sec $8^{\Delta \mathrm{NT}}$, indicating that the inhibition of neurite outgrowth was not caused by induced cell death. This result supports the possibility of the Exocyst complex as a modulator of MTs to mediate vesicle targeting in response to neuronal differentiation. Furthermore, this result demonstrates that the Exocyst complex is a central component in the neurite outgrowth mechanism and, consequently, an important factor in neuronal development.

\section{DISCUSSION}

During neuronal development, vesicles are targeted to specific areas of the plasma membrane. This targeting mechanism ensures the docking and fusion of vesicles exclusively at the growth cone, promoting neurite outgrowth (Dai et al., 1995). In addition, this 
targeting mechanism is likely to be responsible for directing synaptic vesicle precursors to presynaptic sites during synaptogenesis. Several lines of evidence suggest that the Exocyst complex may be involved in this process. First, the Exocyst complex is found in all tissue studied so far, but it is enriched in the brain (Hsu et al., 1996). Second, the Exocyst complex is targeted to sites of membrane addition and has been implied to play a role in targeting vesicles to specific areas of the plasma membrane during cell growth and differentiation (TerBush et al., 1995; Grindstaff et al., 1998; Hazuka et al., 1999). Third, mouse embryos with deletion of the Exocyst subunit $\sec 8$ failed to complete gastrulation and show a delay in neural induction (Friedrich et al., 1997). However, the molecular mechanism and significance of the Exocyst complex function in vesicle targeting during neuronal development is presently unknown. To understand the biological function of the Exocyst complex, we set out to determine its subcellular localization and molecular associations during neuronal differentiation.

We used PC12 cell line as our model system because it has been widely used as a model to study neuronal development and differentiation (Greene et al., 1976; Pang et al., 1995). In this paper, we have shown that the Exocyst has a perinuclear localization in undifferentiated PC12 cells. In contrast, in differentiated PC12 cells and cultured hippocampal neurons, the Exocyst complex redistributes from its perinuclear localization to the extending neurite and concentrates at the growth cone with the vesicle marker Sytg. Interestingly, differential centrif ugation, subcellular fractionation, and pharmacological experiments demonstrate that the Exocyst complex is associated with MTs in both undifferentiated and differentiated PC12 cells. Consistently, the Exocyst complex coimmunoprecipitates with MTs from both PC12 cells and total rat brain lysates, indicating that this association is physiologically significant. These results show, for the first time, that the Exocyst complex may promote targeting of secretory vesicles by directing MTs toward specific domains on the plasma membrane. Interestingly, however, it has been shown that the Exocyst complex coimmunoprecipitated with septins and syntaxin1 (Hsu et al., 1996, 1998). It has been demonstrated that the septins are required during development and cytokinesis (Adam et al., 2000), but their role in these biological processes is still unclear. It may be possible that the Exocyst complex also coordinates the remodeling of septin filaments during cell growth and development. However, it is also possible that the septins may play a role in vesicle trafficking, which requires the Exocyst and/or MT function. In addition, the Exocyst complex might be associated with syntaxin 1 through the cytoskeletal network. Further investigation is required to determine the role of the Exocyst-septins interaction and whether it is a separate association from that between the Exocyst and MTs.

The trophic factor NGF promotes neuronal development by binding to the Trk A receptor, which activates a series of cellular events to promote cell differentiation (Kaplan et al., 2000). One of these events in the neuronal development is the reorganization of MTs toward the future direction of neurite outgrowth (Dent et al., 1999). MTs serve as a railway for the delivery of secretory vesicles to the plasma membrane, and their constant remodeling at the growth cone is essential for growth (Futerman et al., 1996; Zakharenko et al., 1998). We have shown that the Exocyst complex radiates from its perinuclear localization, in association with the MTs, toward the growth cone in response to NGFinduced neuronal differentiation. Interestingly, inhibition of the NGF-induced activation of the MAP kinase pathway blocks neu-

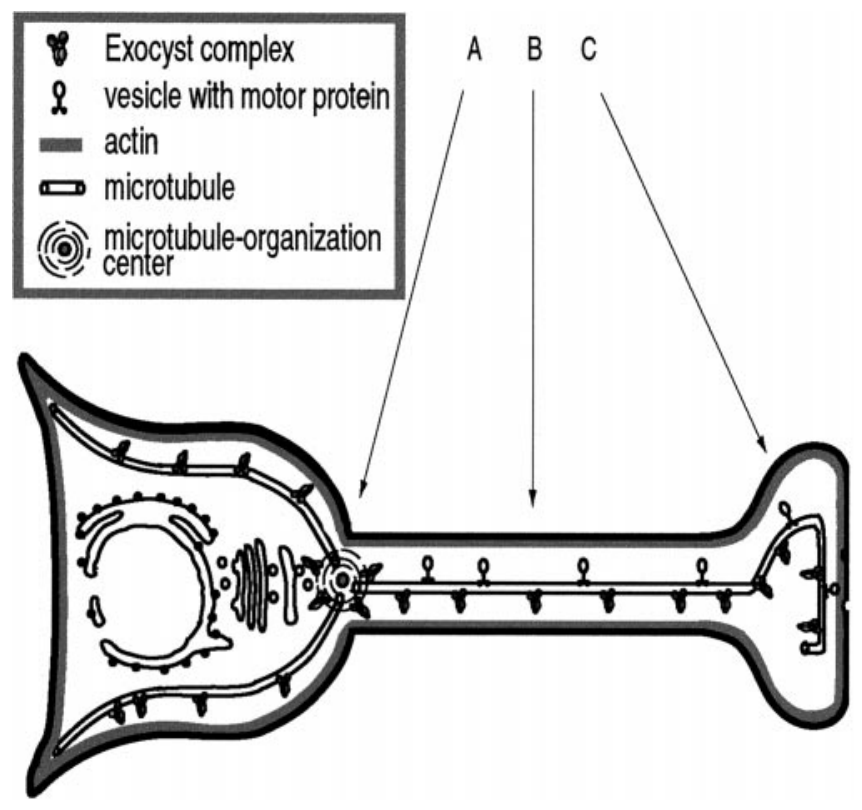

Figure 7. A model of the Exocyst complex function in targeting vesicles toward the growth cone to promote neurite outgrowth. In response to signals that promote cell differentiation, the Exocyst complex coordinates the assembly and redirects the MTs toward specific domains of the plasma membrane. $A$, The Exocyst complex associates with MTs near or at the MTOC before cell differentiation. $B$, On the activation of the cell differentiation process, the Exocyst complex is upregulated. The activated complex functions as a scaffold to coordinate the assembly of MTs and to redirect them to specific areas of the plasma membrane, such as the growth cone. Then, the MTs radiate outward from the MTOC and pave the road by which secretory vesicles are delivered to the vicinity of the plasma membrane via microtubule-associated motors, such as kinesins. $C$, The Exocyst complex associates with the radiating MTs in the extending neurite and the growth cone. Once vesicles are delivered to the growth cone, they are released from the MTs to the plasma membrane. Finally, docking and fusion of these vesicles with the plasma membrane result in membrane addition and/or secretion.

rite outgrowth and abolishes the Exocyst complex and MT redistribution, promoting vesicles to accumulate in the cytoplasm. The importance of the Exocyst complex function in neuronal differentiation is demonstrated by the inhibition of neurite outgrowth in $\mathrm{PC} 12$ cells transfected with the Exocyst $\sec 10^{\Delta \mathrm{CT}}$ deletion mutant. These cells do not extend neurites even in the presence of NGF, indicating that the Exocyst complex is likely to be a downstream effector in the MAP kinase pathway and is essential for neurite outgrowth during neuronal differentiation. This may also explain, in part, the mortality of mouse embryos lacking the Exocyst subunit $\sec 8$ on the initiation of nerve cell differentiation during gastrulation (Friedrich et al., 1997).

On the basis of the above information, we speculate that the Exocyst complex functions as a remodeling factor of MTs to deliver vesicles to specific domains on the plasma membrane (Fig. 7). The Exocyst complex is associated with MTs near or at the MTOC in undifferentiated cells (Fig. 7A). On the activation of the neuronal differentiation process, the Exocyst complex may be upregulated. The activated complex functions as a scaffold to coordinate the assembly of MTs and redirects them toward the growth cone (Fig. $7 B$ ). The redirected MTs serve as a railway to deliver vesicles to specific areas of the plasma membrane. At the growth cone, other factors might facilitate the distribution of vesicles to the vicinity of the plasma membrane. Recently, it has been shown that mutations in the Caenorhabditis elegans RPM-1 
(Schaefer et al., 2000; Zhen et al., 2000), its Drosophila homolog highwire (Wan et al., 2000), and the Drosophila futsch gene (Hummel et al., 2000; Roos et al., 2000) disrupt axon morphology but do not affect axon outgrowth. In particular, mutations in highwire and $R P M-1$ promote abnormal distribution of synaptobrevinGFP vesicles at GABAergic motor terminal but do not affect their delivery. These results indicate that the Exocyst complex plays a central role in promoting neurite outgrowth, but other factors may be required for the proper incorporation of vesicles into the plasma membrane. Finally, collaboration among these proteins promotes the docking and fusion of vesicles with the plasma membrane, resulting in targeted membrane addition or secretion (Fig. 7C).

The Exocyst complex is an essential macromolecule required for secretion in all organisms (from yeast to mammals) and mammalian cells studied so far. It is likely that this complex would have the same or similar molecular function in all organisms and/or cell types. The Exocyst complex may establish the communication between the cell signal transduction pathways and the cytoskeleton network (MTs and septins) to ensure that vesicles are targeted to the appropriate plasma membrane domain. Elucidation of the Exocyst complex biological function is not only important for our understanding of the vesicle targeting pathway in all organisms, but may also provide important insights into specific biological events such as axonal outgrowth during development and regeneration.

\section{REFERENCES}

Adam JC, Pringle JR, Peifer M (2000) Evidence for functional differentiation among Drosophila septins in cytokinesis and cellularization. Mol Biol Cell 11:3123-3135.

Bennett MK, Calakos N, Scheller RH (1992) Syntaxin: a synaptic protein implicated in docking of synaptic vesicles at presynaptic active zones. Science 257:255-259.

Bock JB, Klumperman J, Davanger S, Scheller RH (1997) Syntaxin 6 functions in trans-Golgi network vesicle trafficking. Mol Biol Cell 8:1261-1271.

Bowser R, Muller H, Govindan B, Novick P (1992) Sec8p and Sec15p are components of a plasma membrane-associated $19.5 \mathrm{~S}$ particle that may function downstream of Sec4p to control exocytosis. J Cell Biol 118:1041-1056.

Brinkeley BR (1985) Microtubule organizing centers. Annu Rev Cell Biol 1:145-172.

Dai J, Sheetz MP (1995) Axon membrane flows from the growth cone to the cell body. Cell 83:693-701.

Dent EW, Callaway JL, Szebenyl G, Baas PW, Kalil K (1999) Reorganization and movement of microtubules in axonal growth cones and developing interstitial branches. J Neurosci 19:8894-8908.

Finger FP, Hughes TE, Novick P (1998) Sec3p is a spatial landmark for polarized secretion in budding yeast. Cell 92:559-571.

Friedrich GA, Hildebrand JD, Soriano P (1997) The secretory protein Sec8 is required for paraxial mesoderm formation in the mouse. Dev Biol 192:364-374.

Futerman AH, Banker GA (1996) The economics of neurite outgrowththe addition of new membrane to growing axons. Trends Neurosci 19:144-149.

Greene LA, Tischler A (1976) Establishment of a noradrenergic clonal line of rat adrenal pheochromocytoma cells which respond to nerve growth factor. Proc Natl Acad Sci USA 73:2424-2428.

Grindstaff KK, Yeaman C, Anandasabapathy N, Hsu SC, RodriguezBoulan E, Scheller RH, Nelson WJ (1998) Sec6/8 complex is recruited to cell-cell contact and specifies transport vesicle delivery to the basal-lateral membrane in epithelial cells. Cell 93:731-740.

Guo W, Sacher M, Barrowman J, Ferro-Novick S, Novick P (2000) Protein complexes in transport vesicle targeting. Trends Cell Biol 10:251-255.

Hazuka CD, Foletti DL, Hsu SC, Kee Y, Hopf W, Scheller RH (1999) The sec6/8 complex is located at neurite outgrowth and axonal synapseassembly domains. J Neurosci 19:1324-1334.

Hsu SC, Ting AE, Hazuka CD, Davanger S, Kenny JW, Kee Y, Scheller RH (1996) The mammalian brain rsec6/8 complex. Neuron 17:1209-1219.

Hsu SC, Hazuka CD, Roth R, Foletti DL, Heuser J, Scheller RH (1998) Subunit composition, protein interactions, and structures of the mammalian brain sec6/8 complex and septin filaments. Neuron 20:1111-1122.

Hummel T, Krukkert K, Roos J, Davis G, Klambt C (2000) The Drosophila Futsch/22C10 protein is a MAP1B-like protein required for dendritic and axonal development. Neuron 26:357-370.

Kaibuchi K, Kuroda S, Fukata M, Nakagawa M (1999) Regulation of cadherin-mediated cell-cell adhesion by the Rho family GTPases. Curr Opin Cell Biol 11:591-596.

Kamal A, Goldstein LSB (2000). Connecting vesicle transport to the cytoskeleton. Curr Opin Cell Biol 12:503-508.

Kaplan DR, Willer FD (2000) Neurotrophin signal transduction in the nervous system. Curr Opin Neurobiol 10:381-391.

Kee Y, Yoo JS, Hazuka CD, Peterson KE, Hsu SC, Scheller RH (1997) Subunit structure of the mammalian Exocyst complex. Proc Natl Acad Sci USA 94:14438-14443.

Lane RD, Crissman RS, Ginn S (1986) High efficiency fusion procedure for producing monoclonal antibodies against weak immunogens. Methods Enzymol 121:183-192.

Lowe M, Gonatas NK, Warren G (2000) The mitotic phosphorylation cycle of the cis-Golgi matrix protein GM130. J Cell Biol 149:341-356.

Mellman I, Simons K (1992) The Golgi complex: in vitro veritas? Cell 68:829-840.

Morand JN, Kent C (1986) A one-step technique for the subcellular fractionation of total cell homogenates. Anal Biochem 159:157-162.

Pang L, Sawada T, Decker SJ, Saltiel AR (1995) Inhibition of MAP kinase kinase blocks the differentiation of PC12 cells induced by nerve growth factor. J Biol Chem 270:13585-13588.

Pevsner J, Hsu SC, Braun JEA, Calakos N, Ting AE, Bennett MK, Scheller RH (1994) Specificity and regulation of a synaptic vesicle docking complex. Neuron 13:353-361.

Roos J, Hummel T, Ng N, Klambt C, Davis G (2000) Drosophila Futsch regulates synaptic microtubules organization and is necessary for synaptic growth. Neuron 26:371-382.

Roth D, Guo W, Novick P (1998) Dominant negative alleles of Sec10 reveal distinct domains involved in secretion and morphogenesis in yeast. Mol Biol Cell 9:1725-1739.

Schaefer AM, Hadwiger GD, Nonet ML (2000) Rpm-1, a conserve neuronal gene that regulates targeting and synaptogenesis in C. elegans. Neuron 26:345-356.

Shin DM, Zhao XS, Zeng W, Mozhayeva M, Muallem S (2000) The mammalian Sec6/8 complex interacts with $\mathrm{Ca}^{2+}$ signaling complexes and regulates their activity. J Cell Biol 150:1101-1112.

Sudhoft TC, De Camili P, Niemann H, Jahn R (1993) Membrane fusion machinery: insights from synaptic proteins. Cell 75:1-4.

TerBush DR, Novick P (1995) Sec6, Sec8 and Sec15 are components of a multisubunit complex which localizes to bud tips in Saccharomyces cerevisiae. J Cell Biol 130:299-312.

Ting AE, Hazuka CD, Hsu SC, Kirk MD, Bean AJ, Scheller RH (1995) rSec6 and rSec8, mammalian homologs of the yeast proteins essential for secretion. Proc Natl Acad Sci USA 92:9613-9617.

Wan HI, DiAntonio A, Fetter RD, Bergstrom K, Strauss R, Goodman CS (2000) Highwire regulates synaptic growth in Drosophila. Neuron 26:313-329.

Zakharenko S, Popov S (1998) Dynamics of axonal microtubules regulate the topology of new membrane insertion into the growing neurites. J Cell Biol 143:1077-1086.

Zhen M, Huang X, Bamber B, Jin Y (2000) Regulation of presynaptic terminal organization by $C$. elegans RPM-1, a putative guanine nucleotide exchanger with a Ring-H2 domain. Neuron 26:331-343. 